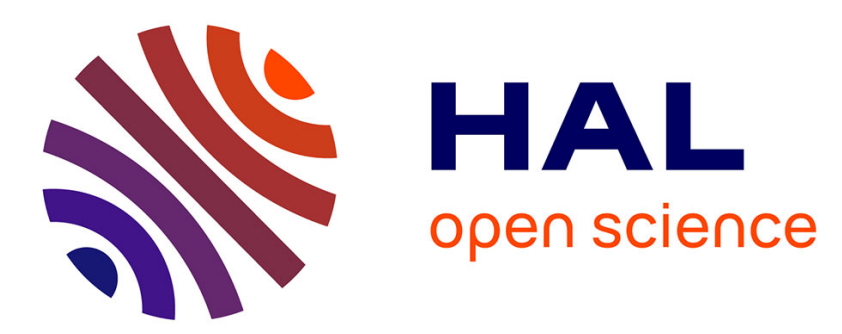

\title{
Sol-gel selection of hybrid G-quadruplex architectures from dynamic supramolecular guanosine libraries
}

\author{
Simona Mihai, Yann Le Duc, Didier Cot, Mihai Barboiu
}

\section{To cite this version:}

Simona Mihai, Yann Le Duc, Didier Cot, Mihai Barboiu. Sol-gel selection of hybrid G-quadruplex architectures from dynamic supramolecular guanosine libraries. Journal of Materials Chemistry, 2010, 20, pp.9443-9448. 10.1039/c0jm01248c . hal-00587204

\section{HAL Id: hal-00587204 https://hal.science/hal-00587204}

Submitted on 19 Apr 2011

HAL is a multi-disciplinary open access archive for the deposit and dissemination of scientific research documents, whether they are published or not. The documents may come from teaching and research institutions in France or abroad, or from public or private research centers.
L'archive ouverte pluridisciplinaire $\mathbf{H A L}$, est destinée au dépôt et à la diffusion de documents scientifiques de niveau recherche, publiés ou non, émanant des établissements d'enseignement et de recherche français ou étrangers, des laboratoires publics ou privés. 


\title{
Sol-gel selection of hybrid G-quadruplex architectures from dynamic supramolecular guanosine libraries $\dagger+$
}

\author{
Simona Mihai, Yann Le Duc, Didier Cot and Mihail Barboiu* \\ Received 28th April 2010, Accepted 2nd July 2010 \\ DOI: $10.1039 / \mathrm{c} 0 \mathrm{jm} 01248 \mathrm{c}$
}

We report an original strategy to transcribe and to fix the self-assembly of G-quadruplex architectures in self-organized nanohybrids. In the first resolution step the G-quartet is pre-amplified in solution in the presence of metal cations from a dynamic pool of ribbon-type or cyclic supramolecular architectures. Then in a second selection sol-gel step the G-quadruplex is irreversibly fixed in a siloxane inorganic network. The interface between the guanosine moiety and the heterosiloxane $\mathbf{3}$ is based on a double reversible covalent iminoboronate connection. This contributes to the high levels of adaptability and correlation in the self-organization of the supramolecular G-quadruplex and the inorganic siloxane systems. Biomimetic-type hybrids can be generated by using this strategy.

\section{Introduction}

Constitutional dynamic chemistry $(\mathrm{CDC})^{1}$ that expresses the adaptive behaviour of molecular and supramolecular systems brings into play the self-evolution of such dynamic systems toward the selection of discrete architectures from mixtures of exchanging components. These concepts may be connected with the simple definition of dynamic multicomponent self-assembly in chemical and biological systems. ${ }^{2}$ The spontaneous formation of higher order superstructures from simple molecular blocks concerns inter-exchanging supramolecular architectures, and often yields discrete devices and materials. By virtue of the reversible interchanges, the components can adapt to internal and external constraints. Kinetic resolution, ${ }^{3,4}$ self-assembly processes followed by covalent modification ${ }^{5}$ or the use of crystallization $^{6,7}$ are useful strategies to control and to drive supramolecular self-organization toward producing functional complex systems. Previous investigations have highlighted the wide potential of resolution strategies controlled in the second step by an irreversible enzymatic ${ }^{3}$ or crystallization ${ }^{6,7}$ tandem process. The control of supra-molecular self-organization by a phase-change can also be driven by using the sol-gel process, ${ }^{6-8}$ providing a simple method for synthesis of well-defined hybrid constitutional materials. ${ }^{5 h}$ In this context, the supramolecular $\mathrm{H}$-bonded macrocycle of four guanine building blocks, the G-quartet, has been proposed as a powerful scaffold for the construction of synthetic supramolecular devices and materials. ${ }^{8}$

The G-quartet architecture represents a dynamic supramolecular system in which the G-quartet is reversibly exchanging with linear ribbons (Fig.1). ${ }^{5 a, b}$ It is stabilized by cations,

Adaptive Supramolecular Nanosystems Group, Institut European des Membranes ENSCM/UMII/UMR CNRS 5635, Place Eugene Bataillon CC047, France. E-mail: mihai.barboiu@iemm.univ-montp2.fr; Fax: (+33) 467149119

$\dagger$ Electronic supplementary information (ESI) available: NMR XPRD and ATG data. See DOI: $10.1039 / \mathrm{c} 0 \mathrm{jm} 01248 \mathrm{c}$

\$ This paper is part of a Journal of Materials Chemistry themed issue on Advanced Hybrid Materials, inspired by the symposium on Advanced Hybrid Materials: Stakes and Concepts, E-MRS 2010 meeting in Strasbourg. Guest editors: Pierre Rabu and Andreas Taubert. templating the eight carbonyl oxygens of two sandwiched G-quartets in the G-quadruplex, the columnar device formed by the vertical stacking of four G-quartets. ${ }^{9}$ It plays a very
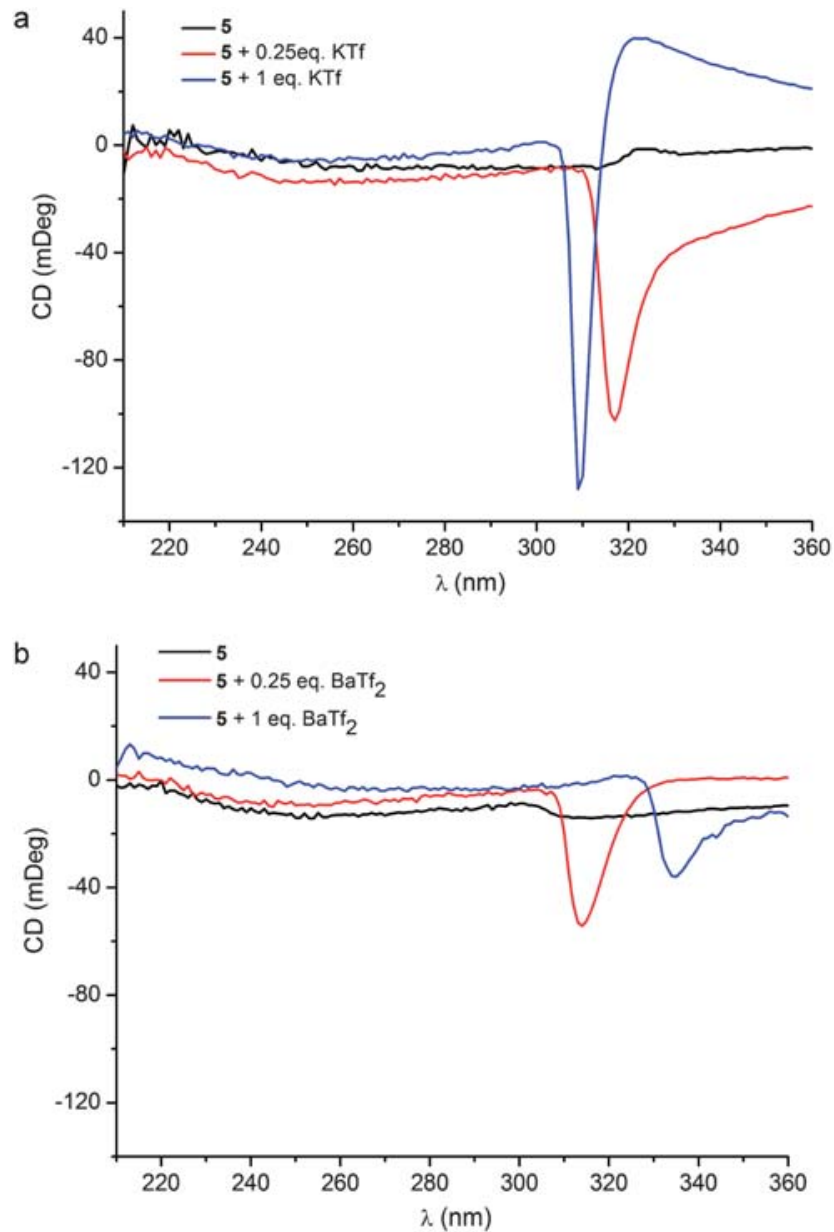

Fig. $1 \mathrm{CD}$ spectra at room temperature in $\mathrm{CH}_{3} \mathrm{OH}$ of $\mathbf{5}\left(10^{-4} \mathrm{M}\right)$ (black line), $\mathbf{5}+0.25$ eq. $\mathrm{KTf}$ or $\mathbf{5}+0.25$ eq. $\mathrm{BaTf}_{2}$ (red line) and $\mathbf{5}+1$ eq. $\mathrm{KTf}$ or $\mathbf{5}+1$ eq. BaTf $_{2}$ (blue line). 
important role in biology in particular in nucleic acid tellomers of potential interest to cancer therapy. ${ }^{8}$ New strategies using reversible polymerization or phase-change-driven selection were successfully used to generate G-quadruplex functional nanostructures. ${ }^{10,11}$ In our group, the guanine building block and the sol-gel chemistry were used to conceive hybrid chiral materials at nanometric and micrometric scales. Our efforts involved the synthesis and the self-assembly of a guanine-siloxane monomer $\mathbf{G}_{\mathbf{S i}}$ (Fig.1), resulting in the formation of G-ribbons, G-quartet and G-quadruplex supramolecular architectures, dynamically exchanging in solution. The generation of G-quadruplex hybrid materials can be achieved by mixing the $\mathbf{G}_{\mathbf{S i}}$ derivative with potassium triflate, where G-quartet superstructures have been amplified. Then the sol-gel selection process has been followed by a second inorganic transcription into inorganic silica replica materials, by calcination. ${ }^{5 a}$ Dynamic nanomaterials, characterized by their aptitude to continuously organize at the macroscopic level the generation of their own components with different blocks forming in coupled equilibria, have been used as a straightforward approach for the design of functional G-quartet membranes ${ }^{5 b}$ and surfaces. ${ }^{11 d}$ Despite such progress, considerable challenges still lie ahead and a more significant one is the dynamic convergence between supramolecular selfassembly of G-quartet architectures and the resolution process (polymerization, phase change). The reversibility of interactions between the G-quartet and polymeric components might be a crucial factor and accordingly, a reversible covalent connection might render the emergence of self-adaptive system mesophases, which may mutually adapt their 3D spatial distribution based on their own structural constitution during the simultaneous formation of mixed self-organized domains.

Herein we report an original strategy to transcribe and to fix the supramolecular self-assembly of the dynamic constitutional G-quartet architectures, in self-organized nanohybrids. ${ }^{12}$ In the first resolution step the G-quartet is pre-amplified in the presence of metal cations from a dynamic pool of oligomeric ribbon-type or cyclic supramolecular architectures (Scheme 1). Then in a second sol-gel step the polycondensation reactions of the inorganic alkoxysilane network take place around the tubular twisted superstructure of the G-quadruplex. It should be noted that the dynamic G-quadruplex architectures are irreversibly fixed in a covalently bonded siloxane network and the structural constitution of the G-quadruplex is transcribed in the hybrid material. These results provides new insights into the basic features that control the convergence of supramolecular selforganization toward functional hybrid materials.

\section{Experimental}

\subsection{Materials and methods}

All reagents were obtained from Aldrich and used without further purification. All organic solutions were routinely dried by using sodium sulfate $\left(\mathrm{Na}_{2} \mathrm{SO}_{4}\right) \cdot{ }^{1} \mathrm{H},{ }^{13} \mathrm{C}$ and ${ }^{29} \mathrm{Si} \mathrm{NMR}$ spectra were recorded on an ARX $300 \mathrm{MHz}$ Bruker spectrometer in d4MeOD using the residual solvent peak as a reference. ${ }^{29} \mathrm{Si}$ MAS NMR was performed on a Bruker ASX 400 spectrometer. ESIMS studies were performed in the positive and negative ion mode using a quadrupole mass spectrometer (Micromass, Platform II). Samples were continuously introduced into the mass spectrometer through a Waters $616 \mathrm{HPLC}$ pump $\left(60^{\circ} \mathrm{C}\right.$; extraction cone voltage: $V \mathrm{c}=30 \mathrm{~V})$. X-ray powder diffraction measurements were performed with $\mathrm{Cu}-\mathrm{K} \alpha$ radiation at $20{ }^{\circ} \mathrm{C}$ using a Philips X'Pert Diffractometer equipped with an Xcelerator detector. Thermogravimetric analysis (Hi-Res TGA 2950, TA Instruments, Nitrogen, $50-600{ }^{\circ} \mathrm{C}$ at $10{ }^{\circ} \mathrm{C} \mathrm{min}^{-1}$ ) and differential scanning calorimetry (DSC 2920 Modulated, TA Instruments) were used to evaluate the thermal stability of the hybrid materials A-E. CD spectra $(220-400 \mathrm{~nm})$ were collected on a MOS-450/ AF-Biologic CD spectrometer with a rate of $0.5 \mathrm{~nm} / \mathrm{step}$, using

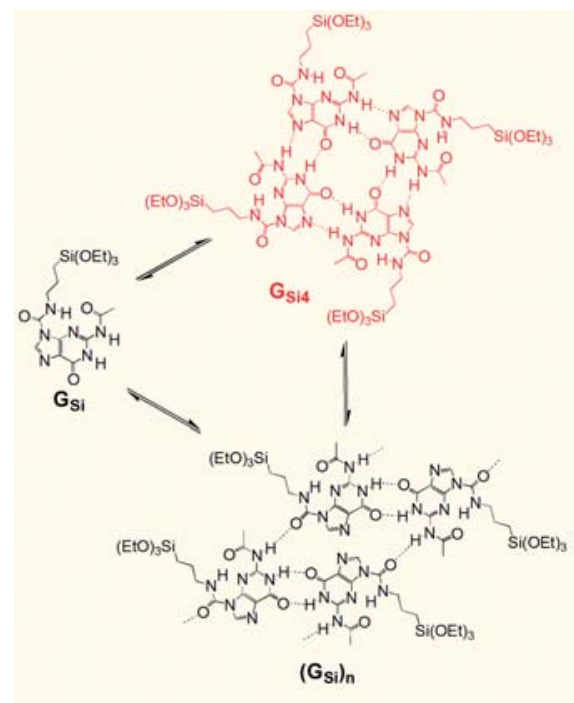

Dynamic supramolecular library

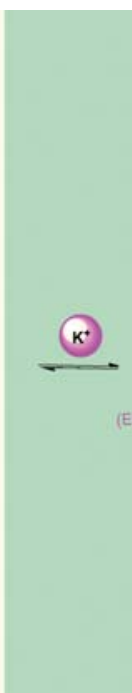

Resolution

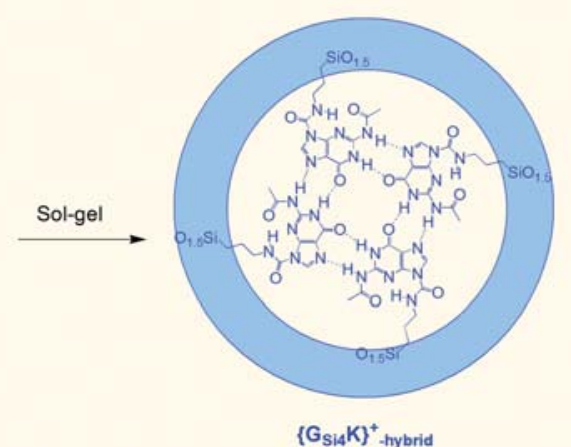

Sol-gel selection

Scheme 1 Cation-template resolution of a dynamic supramolecular guanine system in which the G-quartet is reversibly exchanging with linear ribbons followed by a secondary irreversible sol-gel selection of G-quadruplex hybrid materials. ${ }^{5 a}$ 
$10 \mathrm{~mm}$ quartz cells, at room temperature. The measurements were carried out on $\mathrm{MeOH}$ solutions $\left(10^{-4} \mathrm{M}\right.$ of 3$)$ and on mixtures of $\mathbf{3} / \mathbf{4}(1 / 1, \mathrm{~mol} / \mathrm{mol})$ briefly ultrasonicated with various amounts of $\mathrm{K}^{+}$and $\mathrm{Ba}^{2+}$ ions. The SEM micrographs were obtained with high resolution transmission electron microscopy (HRTEM) JEOL 2010 FEG apparatus, working with an accelerating voltage of $200 \mathrm{kV}$ and a point resolution of $2.0 \AA$.

\subsection{Synthesis of 2-((3-(triethoxysilyl)propylimino)methyl) phenylboronic acid, 3}

3-(triethoxysilyl)propan-1-amine $2(0.8 \mathrm{~mL} ; 3.3 \mathrm{mmol})$ was added to a chloroformic solution $(20 \mathrm{~mL})$ of 2-formyl-phenylboronic acid, 1 ( $0.50 \mathrm{~g} ; 3.3 \mathrm{mmol})$. The mixture was refluxed for $6 \mathrm{~h}$. The solvent was removed under vacuum to give 3 as a yellow oil. (74\%) ${ }^{1} \mathrm{H}-\mathrm{NMR}$ (MeOD, $\left.300 \mathrm{MHz}\right): \delta 0.55$ (t, 2H); 1.04-1.17 $(\mathrm{m}, 9 \mathrm{H}) ; 1.99(\mathrm{~m}, 4 \mathrm{H}) ; 3.33(\mathrm{t}, 2 \mathrm{H}) ; 3.85(\mathrm{dd}, 6 \mathrm{H}) ; 4.55(\mathrm{~s}, 2 \mathrm{H})$; $7.37(\mathrm{~m}, 1 \mathrm{H}) ; 7.57$ (t, 2H); $7.64(\mathrm{~d}, 1 \mathrm{H}) ; 8.71(\mathrm{~s}, 1 \mathrm{H}) .{ }^{13} \mathrm{C}-\mathrm{NMR}$ (MeOD, $300 \mathrm{MHz}): \delta$ 156.7, 153.7, 150.7, 136.2, 136.1, 129.7; $126.8 ; 116.7 ; 106.5 ; 103.0 ; 88.3 ; 87.7 ; 86.5 ; 84.5 ; 84.3 ; 83.1 ; 82.3$; $80.8 ; 61.6$.

\subsection{General procedure for synthesis of $\mathrm{AK}_{\mathrm{K}}{ }^{+}-\mathrm{D}_{\mathrm{K}}{ }^{+}, \mathrm{A}_{\mathrm{Ba}}{ }^{2+}-\mathrm{D}_{\mathrm{Ba}}{ }^{2+}$ and the reference $\mathbf{E}$ hybrid materials}

In a typical run, $3 \mathrm{~mL}$ of methanolic solution of $3\left(2.5 \times 10^{-3} \mathrm{M}\right)$ was mixed with 1 eq. of guanosine $4,0.25$ or 1 eq. of templating metal salt ( $\mathrm{KTf}$ or $\mathrm{BaTf}_{2}$ ) and 3 eq. of benzylamine as catalyst. Whereas hybrids $\mathbf{A}_{\mathbf{K}}{ }^{+}, \mathbf{C}_{\mathbf{K}}{ }^{+}, \mathbf{A}_{\mathbf{B a}}{ }^{2+}, \mathbf{C}_{\mathbf{B a}}{ }^{2+}$ were prepared by a solgel process in the presence of 6 eq. of deionized water the hybrids $\mathbf{B}_{\mathbf{K}}{ }^{+}, \mathbf{D}_{\mathbf{K}}{ }^{+}, \mathbf{B}_{\mathbf{B a}}{ }^{2+}, \mathbf{D}_{\mathbf{B a}}{ }^{2+}$ were prepared by using only the air humidity (Table 1). The solutions were briefly stirred and allowed to react at room temperature under static conditions for 1 week. Then samples were slowly evaporated at room temperature to give yellow powders. A reference sol-gel sample $\mathbf{E}$ was prepared in the absence of ionic salts, under the same conditions.

\section{Results and discussions}

\subsection{Concept, design and synthesis of G-quartet hybrid materials}

3.1.1. Design of hybrid molecular component. 2-((3-triethoxysilyl)propylimino)methyl)phenylboronic acid 3 was obtained by refluxing stoichiometric amounts of 2-formyl-phenylboronic acid 1 and 3-(triethoxysilyl)propan-1-amine 2 in $\mathrm{CHCl}_{3}$ (Scheme 2).

Table 1 The sol-gel synthetic protocol and temperature of $50 \%$ mass decomposition, $T_{50 \%}$ of the hybrid materials, $\mathbf{A}_{\mathbf{K}}{ }^{+}-\mathbf{D}_{\mathbf{K}}{ }^{+}, \mathbf{A}_{\mathbf{B a}}{ }^{2+}-\mathbf{D}_{\mathbf{B a}}{ }^{2+}$

\begin{tabular}{lllllll}
\hline & $\begin{array}{l}3 \\
\text { (equiv.) }\end{array}$ & $\begin{array}{l}\mathbf{4} \\
\text { (equiv.) }\end{array}$ & $\begin{array}{l}\mathrm{KTf} \\
\text { (equiv.) }\end{array}$ & $\begin{array}{l}\mathrm{BaTf}_{2} \\
\text { (equiv.) }\end{array}$ & $\begin{array}{l}\mathrm{H}_{2} \mathrm{O} \\
\text { (equiv.)g }\end{array}$ & $\mathrm{T}_{50 \%}{ }^{\circ} \mathbf{C}$ \\
\hline $\mathbf{A}_{\mathbf{K}}{ }^{+}$ & 1 & 1 & 1 & - & - & 487 \\
$\mathbf{B}_{\mathbf{K}}{ }^{+}$ & 1 & 1 & 1 & - & 6 & 509 \\
$\mathbf{C}_{\mathbf{K}}{ }^{+}$ & 1 & 1 & 0.25 & - & - & 467 \\
$\mathbf{D}_{\mathbf{K}}{ }^{+}$ & 1 & 1 & 0.25 & - & 6 & 450 \\
$\mathbf{A}_{\mathbf{B a}^{2+}}{ }^{2+}$ & 1 & 1 & - & 1 & - & 483 \\
$\mathbf{B}_{\mathbf{B a}^{2+}}$ & 1 & 1 & - & 1 & 6 & 480 \\
$\mathbf{C}_{\mathbf{B}}{ }^{2+}$ & 1 & 1 & - & 0.25 & - & 464 \\
$\mathbf{D}_{\mathbf{B a}}{ }^{2+}$ & 1 & 1 & - & 0.25 & 6 & 473 \\
$\mathbf{E}$ & 1 & 1 & - & - & - & 425 \\
\hline
\end{tabular}

The ${ }^{1} \mathrm{H},{ }^{13} \mathrm{C}$ NMR and ESI-MS spectra are in agreement with the proposed formula.

3.1.2. Generation of G-quartet architectures in solution. Compounds $\mathbf{1}$ and guanosine, $\mathbf{4}$ generate G-quartet architectures by $\mathrm{K}^{+}$or $\mathrm{Ba}^{2+}$ cation templating, based on three-encoded features:

a) the hybrid materials might be considered to contain superstructures resulting from the combination of cross-linked arrays of G-quartets cross-linked by appending iminoboronate groups connected to the silica matrix, reminiscent of the guanine hybrids recently reported by our group; ${ }^{5 a}$

b) the linkage between the guanosine moiety and the iminoboronic monomer, 3 is based on a double reversible covalent connection. The imino moiety contributes to the stabilisation of the reversible boronate-guanosine ester bond by the formation of a dative $\mathrm{N}-\mathrm{B}$ bond. ${ }^{13}$ This then contributes towards dynamic adaptative behaviour on the molecular level in a double "dynamer"-type system: ${ }^{5 b}$ it combines reversible supramolecular $H$-bonding (G-quartets) with the reversible polycondensation (iminoboronate bonds) of components. This might contribute to the high levels of adaptability and correlation in the self-organization of the dynamic supramolecular G-quartets and the rigid inorganic siloxane components;

c) biomimetic guanosine-type hybrids can be generated using this strategy.

The generation of G-quartet architectures can be achieved by using the mixtures of 1 and guanosine $\mathbf{4}(1 / 1, \mathrm{~mol} / \mathrm{mol})$, resulting in the formation of $\mathbf{5}$ and potassium or barium triflates. Unfortunately such mixtures of $5 / \mathrm{KTf}_{\text {or }} \mathrm{BaTf}_{2}$ are soluble only in methanol and the ${ }^{1} \mathrm{H}$ NMR experiments are inadequate to indicate the self-association of the G-quartet due the exchange of $\mathrm{NH}^{1}$ amide and for $\mathrm{NH}^{2}$ amine protons with the solvent.

Next, we used CD spectroscopy to gain evidence that 5 forms supramolecular chiral superstructures in the presence of ions in methanol (Fig. 1). In accordance with the NMR results, a weak Cotton effect was observed in the CD spectrum of a methanolic solution of $\mathbf{5}$ which can be ascribed to the intrinsic supramolecular chirality, resulting from twisted supra-molecular geometry in which the molecular guanosine components associate and indicating that the G-quadruplex is either unstructured or exchanging very fast in solution (Fig. 1a,b black lines). After addition of 0.25 equiv. of $\mathrm{KTf}$ or 0.25 equiv. of $\mathrm{BaTf}_{2}$ the corresponding CD spectra (Fig. 1a,b red lines) shows a negative Cotton effect with a zero crossing at $\lambda=320 \mathrm{~nm}$ or $\lambda=310 \mathrm{~nm}$, respectively in the region of the iminoboronic chromophores. This effect might be induced by the formation of the G-quartets induced by steric interactions between the chiral sugars groups on the $G$ unit and further inducing asymmetric interactions between iminoboronic pendant chromophores. The observed $\mathrm{CD}$ signals in the presence of the cations indicates that chiral aggregates are forming in the presence of metal ions. It is interesting to note that related oligo( $p$-phenylene-vinylene)- $\mathrm{G}^{11 a}$ and oligo-thiophene- $\mathrm{G}^{11 b} D 4$-symmetric octamers, with the appending group attached to the 5 -position of the $G$ ribose, showed a similar negative Cotton effect. Interestingly, increasing the amount of metals ions to 1 equiv. the corresponding CD spectra (Fig. 1a,b blue lines) shows a positive Cotton effect (zero crossing at $\lambda=314 \mathrm{~nm}$ ) for the $\mathrm{K}^{+}$cations and a negative Cotton effect (zero crossing at $\lambda=330 \mathrm{~nm}$ ) for the $\mathrm{Ba}^{2+}$ cations corresponding 


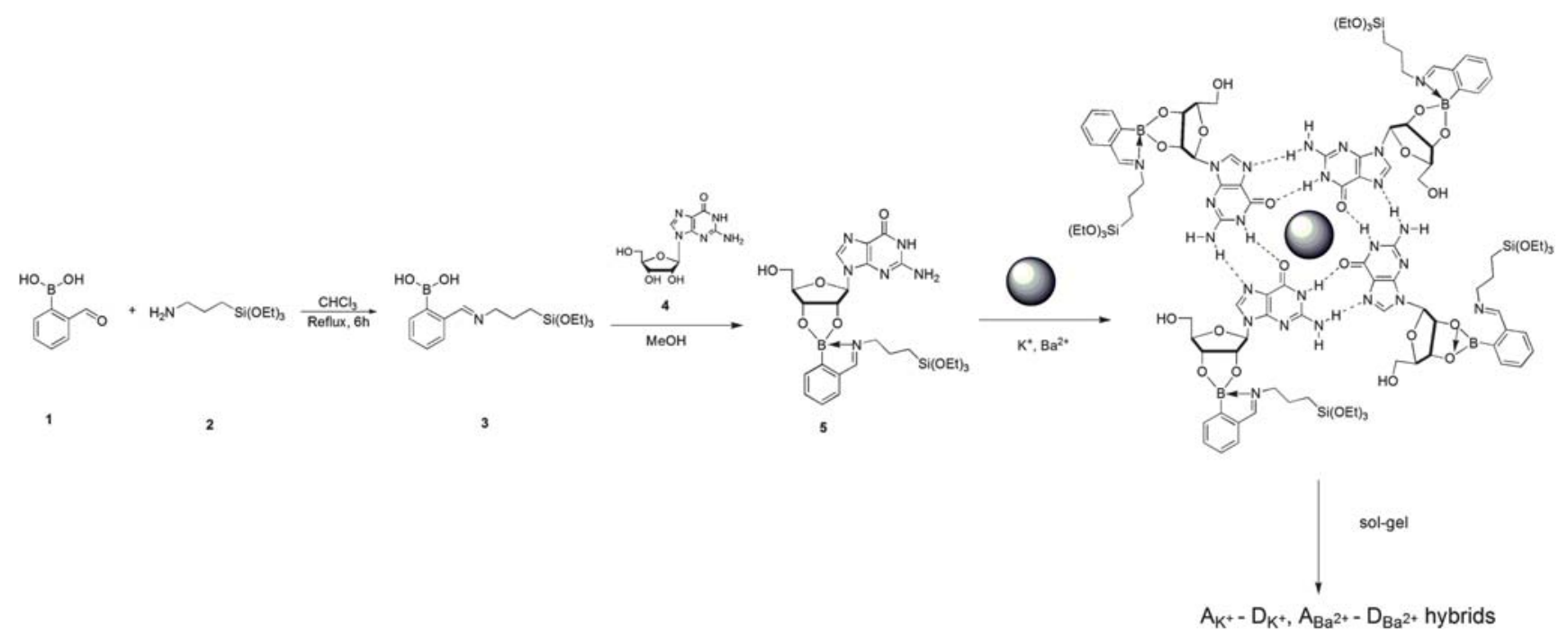

Scheme 2 The synthesis of iminoboronateguanosine precursor 5 followed by ion-template resolution of G-quartet architectures and sol-gel selection of hybrid materials $\mathbf{A}_{\mathbf{K}}{ }^{+}-\mathbf{D}_{\mathbf{K}}{ }^{+}, \mathbf{A}_{\mathbf{B a}}{ }^{2+}-\mathbf{D}_{\mathbf{B a}}{ }^{2+}$.

to a helical self assembly of iminoboronic pendant chromophores. ${ }^{14}$ Moreover this indirect CD signature of chiral superstructures closely resembles the previously calculated CD spectra by Gray et al. ${ }^{15}$ of G-quadruplexes whose adjacent G-quartets have opposite polarities.

3.1.3. Generation of G-quartet architectures in solid state. Having shown that compound 5 equilibrated with $\mathrm{K}^{+}$and $\mathrm{Ba}^{2+}$ ions forms G-quadruplex superstructures in solution we next evaluated their ability to form higher order superstructures in the solid state, by using a sol-gel resolution process. ${ }^{4 a}$ The generation of G-quadruplex hybrid materials $\mathbf{A}_{\mathbf{K}}{ }^{+}-\mathbf{D}_{\mathbf{K}}{ }^{+}$or $\mathbf{A}_{\mathbf{B a}}{ }^{2+}-\mathbf{D}_{\mathbf{B a}}{ }^{2+}$ can be achieved by mixing guanosine $\mathbf{4}$ and 2-((3-(triethoxysilyl)propylimino)methyl)phenyl boronic acid, $\mathbf{3}$ in methanolic solutions with potassium or barium triflates, followed by a solgel process performed at room temperature and using benzylamine as a catalyst (Scheme 2, Table 1). We also carried out the sol-gel process, in the absence of $\mathrm{K}^{+}$or $\mathrm{Ba}^{2+}$ cations, resulting in the formation of a $G$-hybrid material, E. Finally, the organic constituents of these materials have been calcinated to obtain inorganic silica replica architectures induced by the self-organization of G-quadruplex superstructures.

\subsection{FTIR and solid state NMR spectroscopic analyses}

FTIR and NMR spectroscopic analyses demonstrate the formation of a self-organized organic-inorganic network. The FTIR spectra of the hybrid materials $\mathbf{A}_{\mathbf{K}}{ }^{+}-\mathbf{D}_{\mathbf{K}}{ }^{+}, \mathbf{A}_{\mathbf{B a}}{ }^{2+}-\mathbf{D}_{\mathbf{B a}}{ }^{2+}$ or $\mathbf{E}$ allowed us to observe the $\nu_{\mathrm{Si}-\mathrm{O}-\mathrm{Si}}$ broad vibration at 900 $1200 \mathrm{~cm}^{-1}$ instead of $\nu_{\text {Si-OEt }}$ vibrations $\left(950,1070\right.$ and $\left.1100 \mathrm{~cm}^{-1}\right)$ which were noticed for the molecular precursor 3. Clear evidence for $\mathrm{H}$-bonding and metal ions complexation was obtained from FTIR analysis of solids $\mathbf{A}_{\mathbf{K}}{ }^{+}-\mathbf{D}_{\mathbf{K}}{ }^{+}, \mathbf{A}_{\mathbf{B a}}{ }^{2+}-\mathbf{D}_{\mathbf{B a}}{ }^{2+}$ and $\mathbf{E}$. Free $\nu_{\mathrm{C}=\mathrm{O}}=727 \mathrm{~cm}^{-1}$ (hybrid E) was downshifted to $1680 \mathrm{~cm}^{-1}$ (hybrids $\mathbf{A}_{\mathbf{K}}{ }^{+}-\mathbf{D}_{\mathbf{K}}{ }^{+}, \mathbf{A}_{\mathbf{B a}}{ }^{2+}-\mathbf{D}_{\mathbf{B a}}{ }^{2+}$ ), indicating the G-quartets formation (Fig. 2). The formation of iminoboronate esters stabilized by a donor $\mathrm{N} \rightarrow \mathrm{B}$ dative bond is supported the vibration shifts of the $-\mathrm{N}=\mathrm{C}$ bonds: $\nu_{\mathrm{C}=\mathrm{N}}=1640$ to $1605 \mathrm{~cm}^{-1}$ and the presence of the $\nu_{\mathrm{B}-\mathrm{N}}=814 \mathrm{~cm}^{-1}$ band, mostly predominant in the FTIR spectra of $\mathbf{A}_{\mathbf{K}}{ }^{+}-\mathbf{D}_{\mathbf{K}}{ }^{+}, \mathbf{A}_{\mathbf{B a}}{ }^{2+}-\mathbf{D}_{\mathbf{B a}}{ }^{2+}$.

${ }^{29} \mathrm{Si}$ MAS NMR spectroscopic experiments are in agreement for both $\mathbf{A}_{\mathbf{K}}{ }^{+}-\mathbf{D}_{\mathbf{K}}{ }^{+}, \mathbf{A}_{\mathbf{B a}}{ }^{2+}-\mathbf{D}_{\mathbf{B a}}{ }^{2+}$ and the reference $\mathbf{E}$ hybrid materials, with total condensated hybrid materials (the condensation number and the condensation degree are 2.80-2.90 and 93-97\% respectively), with major cross linked $\mathrm{T}^{3} \mathrm{C}-\mathrm{Si}(\mathrm{OSi})_{3}$ (70 ppm $\sim 95 \%$ ) units and minor $\mathrm{T}^{1} \mathrm{C}-\mathrm{Si}(\mathrm{OSi})(\mathrm{OH})_{2}(24 \%), \mathrm{T}^{2}$ $\mathrm{C}-\mathrm{Si}(\mathrm{OSi})_{2}(\mathrm{OH})(59 \mathrm{ppm} \sim 5 \%)$ units, showing a predominant $3 \mathrm{D}$ arrangement. Moreover, that the self assembly processes occur differently in the presence or in the absence of $\mathrm{K}^{+}$templating ions, seems not to influence the hydrolysis-condensation reactions of the alkoxysilane groups during the sol-gel process.

\subsection{X-Ray powder diffraction characterization of G-quadruplex hybrid materials}

Further valuable insights on the self-organization of $\mathbf{A}_{\mathbf{K}}{ }^{+}-\mathbf{D}_{\mathbf{K}}{ }^{+}$or $\mathbf{A}_{\mathbf{B a}}{ }^{2+}-\mathbf{D}_{\mathbf{B a}}{ }^{2+}$ and reference $\mathbf{E}$ hybrid materials are obtained from the X-ray powder diffraction (XPRD) (Fig. 3 and S2 $\dagger$ ).

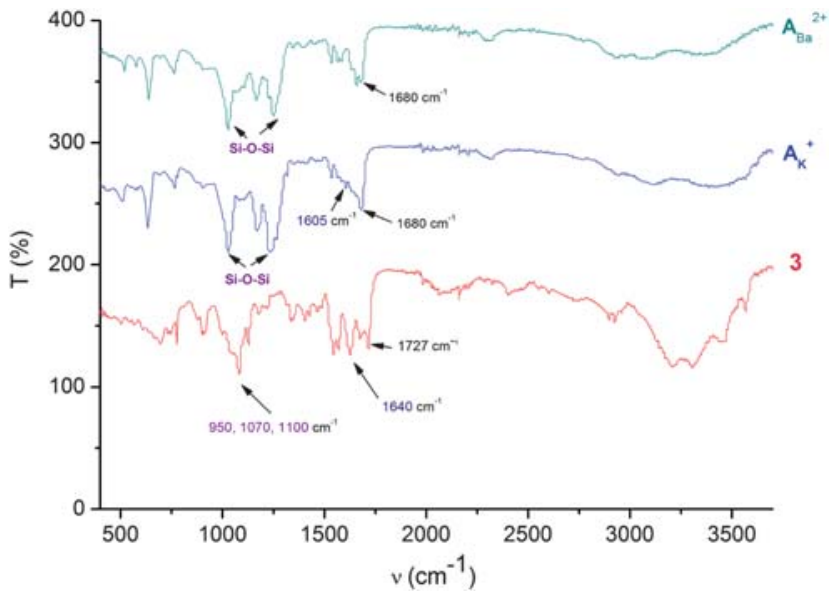

Fig. 2 FTIR spectra of G-hybrid material, $\mathbf{E}$ and of G-quadruplex hybrid materials $\mathbf{A}_{\mathbf{K}}{ }^{+}$and $\mathbf{A}_{\mathbf{B a}}{ }^{2+}$. 

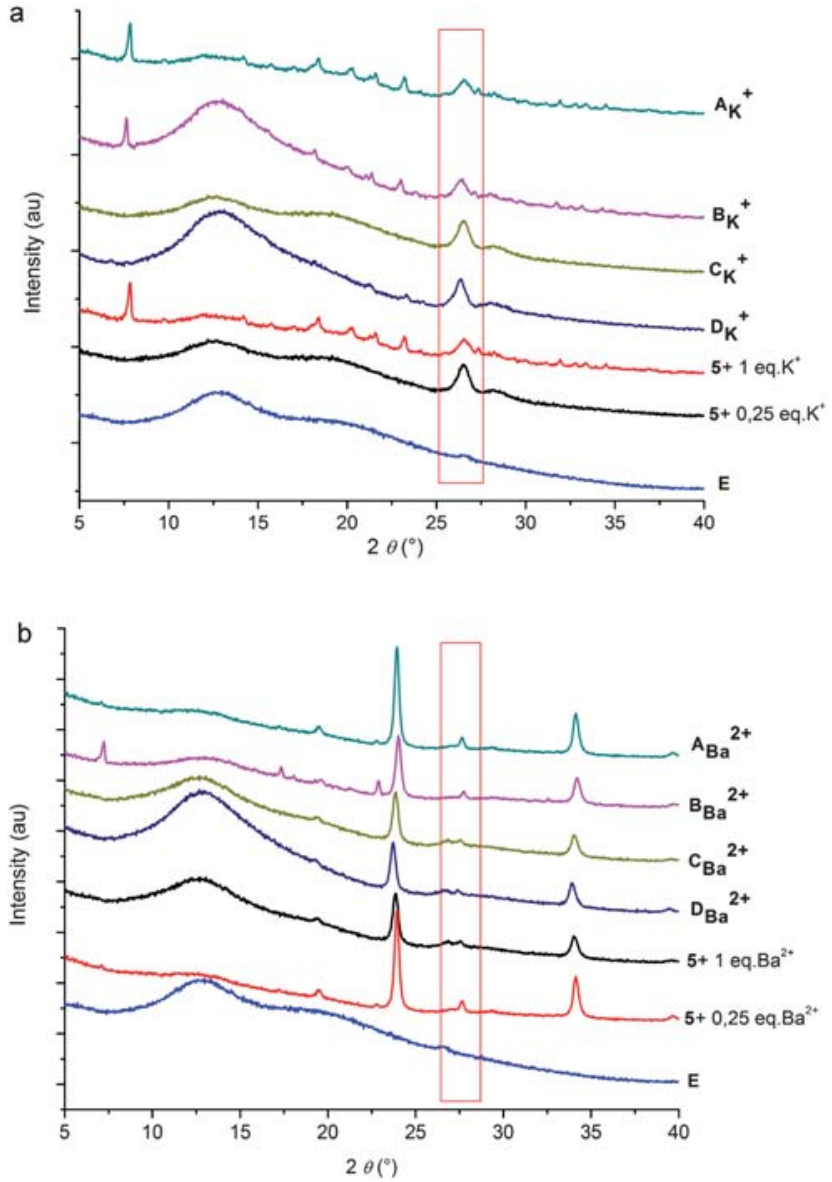

Fig. 3 High angles XPRD patterns of the compounds 5, $5+0.25$ equiv. of $\mathrm{M}^{+}, \mathbf{5}+1$ equiv. of $\mathrm{M}^{+}\left(\mathrm{M}^{+}=\mathrm{K}^{+}, \mathrm{Ba}^{+2}\right)$ and of the hybrid materials a) $\mathbf{A}_{\mathbf{K}}{ }^{+}-\mathbf{D}_{\mathbf{K}}{ }^{+}$and b) $\mathbf{A}_{\mathbf{B a}}{ }^{2+}-\mathbf{D}_{\mathbf{B a}^{2+}}$.

The XRPD patterns of the G-quadruplex hybrids $\mathbf{A}_{\mathbf{K}}{ }^{+}-\mathbf{D}_{\mathbf{K}}{ }^{+}$and $\mathbf{A}_{\mathbf{B a}}{ }^{2+}-\mathbf{D}_{\mathbf{B a}}{ }^{2+}$ present well-resolved peaks (Fig. 3). It is noted that the crystallinity of the $\mathrm{Ba}^{2+}$-templated materials $\mathbf{A}_{\mathbf{B a}}{ }^{2+}-\mathbf{D}_{\mathbf{B a}}{ }^{2+}$ is high compared with the $\mathrm{K}^{+}$-templated analogs, as previously observed $^{16}$ in view of the signal peaks, indicative of long-range structured material. ${ }^{15,16}$ This feature was not observed for the XRPD patterns of the non-templated G-hybrid material, E (Fig. 3, blue, patterns). The metal ion templated materials $\mathbf{A}_{\mathbf{K}}{ }^{+}$$\mathbf{D}_{\mathbf{K}}{ }^{+}$and $\mathbf{A}_{\mathbf{B a}}{ }^{2+}-\mathbf{D}_{\mathbf{B a}}{ }^{2+}$ present a peak at $2 \theta=26.8(d=3.3 \AA)$, representative for the $\pi-\pi$ stacking distance between two planar G-quartets. ${ }^{5 b, 11 e}$ This peak at $2 \theta=26.7^{\circ}(d=3.3 \AA)$, is strongly amplified by simple addition of metal ion templates before the sol-gel process (Fig. 3, the black and red patterns are compared to the blue one) by simply mixing $\mathbf{5}$ with metal ions. Further if we proceed with the sol-gel results in the formation of polymerized hybrids. We observed that the peak at $2 \theta=26.7^{\circ}(d=3.3 \AA)$ is more intense for $\mathbf{C}_{\mathbf{K}}{ }^{+}$and $\mathbf{D}_{\mathbf{K}}{ }^{+}$or $\mathbf{C}_{\mathbf{B a}}{ }^{2+}$ and $\mathbf{D}_{\mathbf{B a}}{ }^{2+}$ materials prepared in the presence of stoichiometric amounts of metal ions.

\subsection{Thermal and morphological studies}

To study the stability of the hybrid materials under the influence of the G-quadruplex superstructure, we explored the thermal
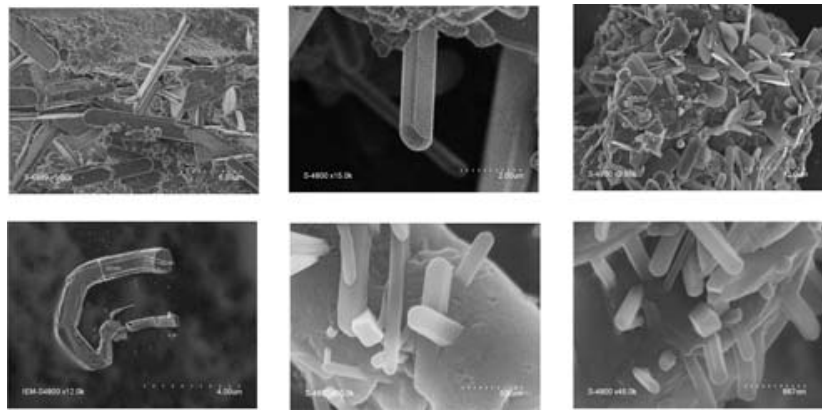

Fig. 4 Scanning electron microscopy images of $\mathbf{B}_{\mathbf{B a}}{ }^{2+}$ hybrid material after the sol-gel step (bottom) and after the calcination step (lower).

decomposition of $\mathbf{A}_{\mathbf{K}}{ }^{+}-\mathbf{D}_{\mathbf{K}}{ }^{+}$or $\mathbf{A}_{\mathbf{B a}}{ }^{2+}-\mathbf{D}_{\mathbf{B a}}{ }^{2+}$ and reference $\mathbf{E}$ hybrid materials. Table 1 shows the $T_{50 \%}$ temperature for which $50 \%$ weight decomposes. The formation G-quadruplex structures induce a higher $T_{50 \%}$ for $\mathbf{A}_{\mathbf{K}}{ }^{+}-\mathbf{D}_{\mathbf{K}}{ }^{+}$and $\mathbf{A}_{\mathbf{B a}}{ }^{2+}-\mathbf{D}_{\mathbf{B a}}{ }^{2+}$ materials than reference material $\mathbf{E}$. Scanning electron microscopy (SEM) micrographs reveal that the hybrid materials $\mathbf{A}_{\mathbf{K}}{ }^{+}-\mathbf{D}_{\mathbf{K}}{ }^{+}$ and $\mathbf{A}_{\mathbf{B a}}{ }^{2+}-\mathbf{D}_{\mathbf{B a}}{ }^{2+}$ (Fig. 4) have micrometric plate-like or nanorod morphologies. Moreover, while the classical hybrids are compact dense solids with a granular morphology, the constitutional hybrids $\mathbf{A}_{\mathbf{i}}$ and $\mathbf{B}_{\mathbf{i}}$ consist of crystalline rods of micrometric dimension. It is interesting to note that similar superior longrange organisation at micrometric length have been previously observed. ${ }^{16}$ This phenomenon is certainly dependent on the superior emergence of collective domains adapting along the G-quadruplex reversible interfaces. This may increase the size of self-organized domains, increasing the dimension of resulted microdomains of such constitutional hybrids. ${ }^{16}$

\section{Conclusions}

In conclusion, the results presented here reveal an original strategy to transcribe and to fix supramolecular G-quadruplex architectures in self-organized constitutional hybrids. In particular, the use of a dynamic iminoboronate interface between the organic (supramolecular) and inorganic siloxane networks represents a useful strategy for improving their compatibility. Dynamic self-assembly of supramolecular systems prepared under thermodynamic control, may in principle be connected to a kinetically controlled sol-gel process in order to extract and select the interpenetrated self-organized networks under a specific set of experimental conditions. Such "dynamic convergence" between supramolecular self-assembly and an inorganic sol-gel process which can synergistically communicate, leads to higher self-organized hybrid materials with increased micrometric scales. Sol-gel selection of constitutional architectures from dynamic combinatorial libraries toward systems materials, as highly interconnected networks of reactional and constitutional materials, should expand the fundamental understanding of nanoscale structures and properties as it relates to creating products and manufacturing processes. More generally, applying such consideration to hybrid materials, leads to the definition of constitutional hybrid materials, in which organic (supramolecular)/inorganic domains are reversibly connected. ${ }^{17}$ Considering the simplicity of this strategy, possible applications 
of the synthesis to more complex architectures might be very effective, producing novel expressions of complex matter.

\section{Acknowledgements}

This work, conducted under the European Heads of Research Councils and European Science Foundation EURYI (European Young Investigator) Awards scheme in 2004, was supported by funds from the participating organizations of EURYI and the EC Sixth Framework Program. See www.esf.org/euryi.

\section{Notes and references}

1 (a) J.-M. Lehn, Chem. Soc. Rev., 2007, 36, 151-160; (b) J. A. Thomas, Chem. Soc. Rev., 2007, 36, 856-868; (c) M. Barboiu and J.-M. Lehn, Proc. Natl. Acad. Sci. U. S. A., 2002, 99, 5201-5206.

2 (a) M. Kindermann, I. Stahl, M. Reimond, W. M. Pankau and G. von Kiedrovski, Angew. Chem., Int. Ed., 2005, 44, 6750-6755; (b) J. Stankiewicz and L. H. Eckardt, Angew. Chem., Int. Ed., 2006, 45, 342-344; (c) R. F. Ludlow and S. Otto, Chem. Soc. Rev., 2008, 37, $101-108$.

3 (a) P. Vongvilai, M. Angelin, R. Larsson and O. Ramström, Angew. Chem., Int. Ed., 2007, 46, 948-950; (b) R. Larsson and O. Ramström, Eur. J. Org. Chem., 2006, 285-291; (c) R. Larsson, Z. Pei and O. Ramström, Angew. Chem., Int. Ed., 2004, 43, 37163718; (d) M. Angelin, P. Vongvilai, A. Fischer and O. Ramström, Chem. Commun., 2008, 768-770; (e) M. Angelin, P. Vongvilai, A. Fischer and O. Ramström, J. Org. Chem., 2008, 73, 3593-3595.

4 (a) S. Xu and N. Giuseppone, J. Am. Chem. Soc., 2008, 130, 18261827; (b) R. Nguyen, L. Allouche, E. Buhler and N. Giuseppone, Angew. Chem., Int. Ed., 2009, 48, 1093-1096 and references therein; (c) R. Nguyen, E. Buhler and N. Giuseppone, Macromolecules, 2009, 42, 5913-5915; (d) L. Tauk, A. P. Schröder, G. Decher and N. Giuseppone, Nat. Chem., 2009, 1, 649-654.

5 (a) C. Arnal-Hérault, M. Michau, A. Pasc-Banu and M. Barboiu, Angew. Chem., Int. Ed., 2007, 46, 4268-4272; (b) C. Arnal-Hérault, A. Pasc-Banu, M. Michau, D. Cot, E. Petit and M. Barboiu, Angew. Chem., Int. Ed., 2007, 46, 8409-8413; (c) M. Michau, M. Barboiu, R. Caraballo, C. Arnal-Hérault, P. Periat, A. van der Lee and A. Pasc, Chem.-Eur. J., 2008, 14, 1776-1783; (d) A. Cazacu, C. Tong, A. van der Lee, T. M. Fyles and M. Barboiu, J. Am. Chem. Soc., 2006, 128, 9541-9548; (e) M. Barboiu, G. Vaughan and A. van der Lee, Org. Lett., 2003, 5, 3073-3076; $(f)$ M. Barboiu, J. Inclusion Phenom. Macrocyclic Chem., 2004, 49, 133-137; $(g)$ M. Barboiu, S. Cerneaux, A. van der Lee and G. Vaughan, J. Am. Chem. Soc., 2004, 126, 3545-3550; (h) C. Arnal-Hérault, M. Barboiu, A. Pasc, M. Michau, P. Perriat and A. van der Lee, Chem.-Eur. J., 2007, 13, 6792-6800.

6 (a) P. N. W. Baxter, J.-M. Lehn and K. Rissanen, Chem. Commun., 1997, 1323-1324; (b) M. Hutin, C. J. Cramer, L. Gagliardi, L. A. R. Shahi, G. Bernardinelli, R. Cerny and J. R. Nitschke, J. Am. Chem. Soc., 2007, 129, 8774-8780; (c) P. N. W. Baxter, J.-M. Lehn, G. Baum and D. Fenske, Chem.-Eur. J., 2000, 6, 45104517; (d) C. D. Pentecost, K. S. Chichak, A. J. Peters, G. W. V. Cave, S. J. Cantrill and J. F. Stoddart, Angew. Chem., Int. Ed., 2007, 46, 218-222; (e) C.-F. Chow, S. Fujii and J.-M. Lehn, Chem. Commun., 2007, 4363-4365; (f) A. Müller, L. Toma, H. Bogge, C. Scaffer and A. Stammler, Angew. Chem., Int. Ed., 2005, 44, 7757-7761.

7 (a) F. Dumitru, E. Petit, A. van der Lee and M. Barboiu, Eur. J. Inorg. Chem., 2005, 4255-4262; (b) Y. M. Legrand, A. van der Lee and M. Barboiu, Inorg. Chem., 2007, 46, 9540-9547; (c) M. Barboiu, E. Petit, A. van der Lee and G. Vaughan, Inorg. Chem., 2006, 45, 484-486; (d) M. Barboiu, F. Dumitru, Y.-M. Legrand, E. Petit and A. van der Lee, Chem. Commun., 2009, 2192-2194; (e) F. Dumitru, Y. M. Legrand, A. van der Lee and M. Barboiu, Chem. Commun., 2009, 2667-2669; (f) E. Mahon, T. Aastrup and M. Barboiu, Chem.
Commun., 2010, 46, 2441-2443; ( $g$ ) E. Mahon, T. Aastrup and M. Barboiu, Chem. Commun., 2010, 46, 5491, DOI: 10.1039/ $\mathrm{c} 002652 \mathrm{~b}$.

8 (a) J. T. Davis and G. P. Spada, Chem. Soc. Rev., 2007, 36, 296-313; (b) J. T. Davis, Angew. Chem., Int. Ed., 2004, 43, 668-698.

9 (a) T. Giorgi, S. Lena, P. Mariani, M. A. Cremonini, S. Masiero, S. Pieracini, J. P. Rabe, P. Samori, G. P. Spada and G. Gotarelli, J. Am. Chem. Soc., 2003, 125, 14741-17479; (b) S. Pieraccini, S. Masiero, O. Pandoli, P. Samori, G. P. Spada and G. Gotarelli, Org. Lett., 2006, 8, 3125-3128.

10 (a) A. Ghoussoub and J.-M. Lehn, Chem. Commun., 2005, 5763-5765; (b) V. Setnicka, M. Urbanova, K. Volka, S. Nampally and J.-M. Lehn, Chem.-Eur. J., 2006, 12, 8735-8743; (c) N. Sreenivasachary and J.-M. Lehn, Chem.-Asian J., 2008, 3, 134 139; (d) W. C. Drewe and S. Neidle, Chem. Commun., 2008, 52955297; (e) C. Graziano, S. Masiero, S. Pieracini, M. Lucarini and G. P. Spada, Org. Lett., 2008, 10, 1739-1742; (f) E. Buhler, S. Nampally, S.-J. Candau and J.-M. Lehn, J. Am. Chem. Soc., 2007, 129, 10058-10059; (g) M. Nikan and J. C. Sherman, Angew. Chem., Int. Ed., 2008, 47, 4900-4902.

11 (a) D. Gonzalez-Rodriguez, P. G. A. Janssen, R. Martin-Rapun, I. De Cat, S. De Feyter, A. P. H. J. Schenning and E. W. Meijer, J. Am. Chem. Soc., 2010, 132, 4710-4719; (b) S. Pieraccini, S. Bonacchi, S. Lena, S. Masiero, M. Montalti, N. Zaccheroni and G. P. Spada, Org. Biomol. Chem., 2010, 8, 774-781; (c) S. Lena, S. Masiero, S. Pieraccini and G. P. Spada, Chem.-Eur. J., 2009, 15, 7792-7806; (d) A. Ciesielski, S. Lena, S. Masiero, G. P. Spada and P. Samori, Angew. Chem. Int. Ed., 2010, 49, 1963-1966; (e) M. Li, R. J. Oakley, H. Bevan, B. M. Smarsly, S. Mann and C. F. J. Faul, Chem. Mater., 2009, 21, 3270-3274.

12 (a) C. Sanchez, H. Arribart and M. M. Girau-Guille, Nat. Mater., 2005, 4, 277-288; (b) J. J. E. Moreau, L. Vellutini, M. Wong Chi Man, C. Bied, J. L. Bantignies, P. Dieudonné and J. L. Sauvajol, J. Am. Chem. Soc., 2001, 123, 7957-7958; (c) R. J. P. Corriu, Eur. J. Inorg. Chem., 2001, (5), 1109-1121; (d) K. J. C. van Bommel, A. Frigerri and S. Shinkai, Angew. Chem., Int. Ed., 2003, 42, 980999; (e) M. Barboiu, C. Guizard, C. Luca, B. Albu, N. Hovnanian and J. Palmeri, J. Membr. Sci., 1999, 161, 193-206; $(f)$ M. Barboiu, C. Guizard, C. Luca, N. Hovnanian, J. Palmeri and L. Cot, J. Membr. Sci., 2000, 174, 277-286; $(g)$ M. Barboiu, C. Guizard, N. Hovnanian, J. Palmeri, C. Reibel, C. Luca and L. Cot, J. Membr. Sci., 2000, 172, 91-103; (h) O. Villamo, C. Barboiu, M. Barboiu, W. Yau-Chun-Wan and N. Hovnanian, J. Membr. Sci., 2002, 204, 97-110; (i) C. Guizard, A. Bac, M. Barboiu and N. Hovnanian, Sep. Purif. Technol., 2001, 25, 167-180; (j) M. Barboiu, N. Hovnanian, C. Luca and L. Cot, Tetrahedron, 1999, 55, 9221-9232; (k) M. Barboiu, C. Luca, C. Guizard, N. Hovnanian, L. Cot and G. Popescu, J. Membr. Sci., 1997, 129, 197-207; (l) M. Barboiu, C. Guizard, N. Hovnanian and L. Cot, Sep. Purif. Technol., 2001, 25, 211-218; (m) M. Michau, R. Caraballo, C. Arnal-Hérault and M. Barboiu, J. Membr. Sci., 2008, 321, 22-30; (n) M. Michau and M. Barboiu, J. Mater. Chem., 2009, 19, 6124-6131.

13 (a) T. D. James, H. Shinmori and S. Shinkai, Chem. Commun., 1997, 71-72; (b) L. Zhu, S. H. Shabbir, M. Gray, V. M. Lynch, S. Sorey and E. V. Anslyn, J. Am. Chem. Soc., 2006, 128, 1222-1232; (c) A. M. Kelly, Y. Pérez-Fuertes, S. Arimori, S. D. Bull and T. D. James, Org. Lett., 2006, 8, 1971-1974.

14 (a) K. Hanabusa, M. Yamada, M. Kimura and H. Shirai, Angew. Chem., Int. Ed. Engl., 1996, 35, 1949-1951; (b) K. Hanabusa, K. Shimura, K. Hirose, M. Kimura and H. Shirai, Chem. Lett., 1996, 25, 885-886.

15 D. M. Gray, J.-D. Wen, C. W. Gray, R. Repges, C. Repges, G. Raabe and J. Fleinschhauer, Chirality, 2008, 20, 431-440.

16 S. Mihai, A. Cazacu, C. Arnal-Herault, G. Nasr, A. Meffre, A. van der Lee and M. Barboiu, New J. Chem., 2009, 33, 2335-2343.

17 A. Cazacu, Y. M. Legrand, A. Pasc, G. Nasr, A. van der Lee, E. Mahon and M. Barboiu, Proc. Natl. Acad. Sci. U. S. A., 2009, 106, 8117-8122. 